Volume 9, No.1.4, 2020

International Journal of Advanced Trends in Computer Science and Engineering

Available Online at http://www.warse.org/IJATCSE/static/pdf/file/ijatcse7391.42020.pdf

https://doi.org/10.30534/ijatcse/2020/7391.42020

\title{
Autonomous Vehicle Repositioning System for Double-Parking
}

\author{
Muhammad Rusydi Muhammad Razif ${ }^{1}$, Mohamad Ridzwan Hosaini ${ }^{2}$, Muhammad Rafiq Kazi Hosaini ${ }^{3}$, \\ Ili Najaa Aimi Mohd Nordin ${ }^{4}$, Amirul Syafiq Sadun ${ }^{5}$ \\ 1,2,4,5 Faculty of Engineering Technology, Universiti Tun Hussein Onn Malaysia, Malaysia, rusydi@ uthm.edu.my \\ ${ }^{3}$ R\&R Glocal Service Sdn. Bhd., Pasir Gudang, Johor, Malaysia, muhamadrafiq5121@ gmail.com \\ 1,4,5 Cybernetics Focus Group, Advanced Technology Centre, Universiti Tun Hussein Onn Malaysia, Malaysia, \\ ilinajaa@uthm.edu.my,amirul@uthm.edu.my
}

\begin{abstract}
Double parking is commonly practiced in crowded areas where parking facilities are limited. Normally, the double-parked vehicle owner will leave their phone number on the vehicle or release the handbrake. However, there are number of cases that the owner forgot to take the action and causing problem for the blocked vehicle to leave the parking lot. This research will focus on solving the double parking issues by proposing an automatic approach for the vehicle to reposition itself and it is equipped with a notification system for the owner. The autonomous system started when a sound sensor detect a horn sound from the blocked vehicle. Then, the system will automatically start the engine and shift the gear position from neutral to reverse. At the same time, the brake system will functioning and it will released the brake about 5 seconds or 3.45 meters, when no obstacle behind the vehicle. The distance is set to 3.45 meters because it is enough for the blocked vehicle to leave the parking space. If there is any obstacle behind the vehicle, the autonomous system will not release the brake and the repositioning will be considered unsuccessful. After the repositioning process completed either success or not, the system will send a notification to the double-parked owner mobile phone through SMS immediately to alert the owner, regarding to their vehicles status. Based on the experiment, the autonomous vehicle repositioning system is able to move the blocked vehicle automatically to the new position as desired and success in sending notification to the owner regarding to their vehicle repositioning condition status.
\end{abstract}

Key words : Autonomous, double parking, vehicle, reposition, SMS.

\section{INTRODUCTION}

Most cities have areas where the provision of parking supply is unable to meet peak period demand [1]. The lack of parking facilities, an inadequate driver's education and poor policing have led to illegal parking phenomena in many cities. In some crowded areas, especially in urban areas, information about parking occupancy is still lacking [2] and the result will cause a serious problem related to the parking. Example of the illegal parking violation cases includes parking on private spaces or spaces for special user such as reserved for disabled people, double-parking, parking on bus-lanes or bus stops, parking on pedestrian crossings, parking near signalized intersections and parking on corners. This situation causes traffic disruption and increases the risks of road accidents [3].

Double-park means to park a car illegally next to a car that is already parked at the side of the road. The double-parked vehicle will block some vehicles and prevent it to leave the parking area. Usually, the double-parked vehicle owner will leave the handbrake off or leave their contact number. Then, the drivers of a blocked vehicle need to push the double-parked car to have enough space to leave the parking lot. Autonomous car defined as a vehicle that is capable of sensing its environment and moving with little or no human intervention [4]. Many studies related to the autonomous vehicle concept had been conducted and some of them already implemented in commercial car. Basically, the autonomous car concept is achieved by combining various sensors in a car, which are integrated together to perceive the vehicle surrounding using an intelligent control system. The system usually able to control the speed of the vehicle and the vehicle's brake automatically based on various sensor input. Then, all the data from the sensors are processed to perform the specific function in a modern vehicle. Many autonomous systems for vehicle had been introduced such as Adaptive Cruise Control (ACC) also known as auto-pilot system, emergency brake assist system and Intelligent Parking Assist System (IPAS) [5] as well as the parking system for autonomous vehicle [6]. However, all the system discussed used for driving aids purpose and a human engagement is still needed to ensure the safety of the drive with little effort. 
In ACC system [7], a radar attached in front of the vehicle is used to detect if there are any slower moving vehicles in the ACC vehicle's path. If a slower moving vehicle is detected, the ACC system will slow down the vehicle and control the clearance, or time gap, between the ACC vehicle and the forward vehicle [8]. If the system detects that the forward vehicle is no longer in the ACC vehicle's path, the ACC system will accelerate the vehicle back to its set cruise control speed. The method used in ACC vehicle's speed adjustment is by controlling the vehicle's engine throttle and brake operation.

In Intelligent Parking Assist System (IPAS), driver allows designating target position by four complementary methods, which are monocular vision, based parking slot marking recognition, ultrasonic sensor based parallel parking slot recognition, and drag and drop Graphical User Interface (GUI). IPAS will generate an optimal path to reach the designated target position. During parking operations, IPAS estimates ego-vehicle pose using Electronic Stability Program (ESP) sensors such as wheel speed sensors, braking pedal switch and steering angle sensor. IPAS automatically controls braking and steering to achieve planned trajectory by sending required actuations to ESP and Electric Power Steering (EPS). Furthermore, IPAS will informs driver of the on-going parking operation by showing estimated trajectory on the rear view image [5].

In autonomous vehicle system, the important part is to ensure safety for the user and other people. To ensure the safety, Geronimi et al. introduced an Automatic Emergency Braking System (AEBS) [9]. The AEBS is an autonomous road vehicle safety system which employs sensors to monitor the distance of vehicles in front. The microcontroller will detect situations where the relative speed and distance between the host and target vehicles to suggest if a collision is imminent [10]. In such situation, emergency braking can be automatically function to avoid collision or at least mitigate its effects. The brake operation is controlled by solenoid pump installed inside hydraulic system of the vehicle's brake. Another vehicle safety method proposed by Ali et al. use an Intelligent Transportation System, where the vehicles can communicate between vehicle to vehicle and vehicle to infrastructure to avoid collision [11].

For the notification system in parking issues, an idea proposed for home security system using GSM network [12]-[14] might be useful. The purpose of the invention to home security system was to provide a security device, which gives immediate notification to the owner and security services like police station or fire brigade at the moment the unauthorized event occurs. This was accomplished via microcontroller which detects the unauthorized event based on the input from various sensors installed at home for security purposed. Then, the microcontroller activates the GSM module to send one or more SMS to the owner and corresponding security services. This method seems to be practical for autonomous vehicle notification by changing the input from the sensors for home security system to the reverse sensor in autonomous vehicle. Based on the previous studies done by other researchers, the autonomous vehicles have the capability to perform the automatic driving with the acceptable safety features. These indicate that the idea of autonomous repositioning vehicle on double parking is possible to be implement on the autonomous vehicles with additional features such as sound recognition to turn on the system and notification system to notify the current condition of the vehicle to the owner.

\section{SOUND RECOGNITION SYSTEM}

In double parking situation, the sound recognition system is use to sense the command from the blocked vehicle in kind of horn sound. This process is needed to initiate the repositioning process and to avoid any irrelevant operation. The command should be specific to ensure the repositioning process only operated when necessary without disturbance of any accidental situation or noise disturbance. The sound recognition system consists of sound sensor module and microcontroller. The sound sensor will detect the sound signal from environment and convert it into electrical signal. Then, the sound sensor will send the signal into microcontroller to perform analyzing process. In this study, the sound recognition system is used to initiate the repositioning process by detecting the horn command from the blocked vehicle and then start the vehicle's engine. To accomplish this, after the sound recognition system has been activated, it should automatically able to control the car's ignition switch to turn on the power and drive the starter motor. However, the microcontroller used in the studies is Arduino Mega, which is designed with $5 \mathrm{~V}$ voltage base system while most of the automobile vehicle used $12 \mathrm{~V}$ as a voltage base. Based on this situation, an intermediate circuit need to be introduced which is relay module which commonly used in between the control circuit and the main circuit. Then, the control circuit will provide a low voltage and cur-rent while main circuit remain in high voltage and current.

In this research, relay module HS-58S is used to allow the microcontroller Arduino Mega to control the car's ignition switch in order to drive the starter motor. Figure 1 shows the flow process for the sound recognition system. Referring to the Figure 1, the battery sensor function as a voltage sensor, which used to pre-determine the engine condition. It is connected to the battery terminal to detect the voltage level of the battery. The nominal battery level for most autonomous vehicle is $12 \mathrm{~V}$ in normal condition and $13.5 \mathrm{~V}$ in charging condition. By sensing the difference in battery voltage level, 
the Arduino Mega will able to drive and stop the starter motor as soon as the engine run. This process is important to ensure that the starter motor does not over run to avoid the damage. Figure 2 shows the hardware set up for the sound recognition system. The sound recognition is programmed to detect the horn sound in specific sequence, which has been set to be 4 times in a row.

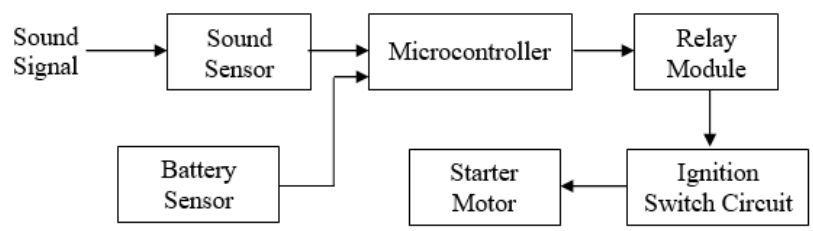

Figure 1: Sound recognition system process

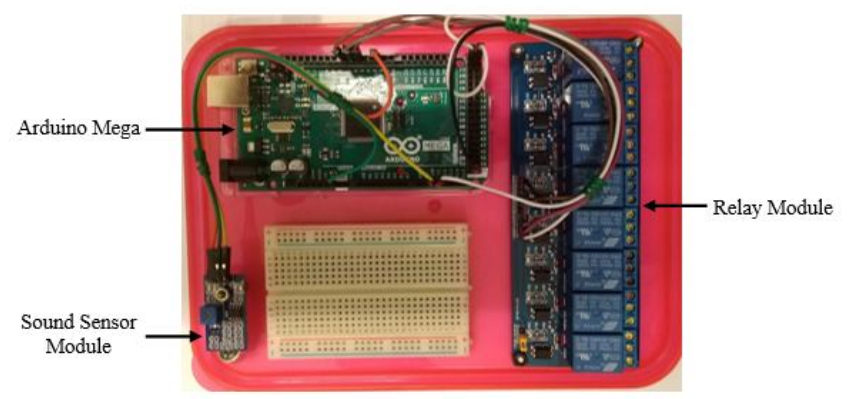

Figure 2: Hardware set up for sound recognition system

\section{AUTOMATIC DRIVE SYSTEM}

The aim of automatic drive system in this research is to allow the vehicle to move and stop in linear direction. After the vehicle's engine is successfully started using the sound recognition system, the automatic drive system will take place by automatically shift the gear lever from Neutral $(\mathrm{N})$ to Reverse $(\mathrm{R})$ position. Then, the brake will slowly release and the vehicle will begin to move in reverse direction. After a few seconds, the brake will automatically pressed again causing the vehicle to slow down until finally stop. In order to accomplish the repositioning process, the system should be able to control the vehicle's transmission and brake. Hence, two mechanisms are designed for this purpose, which are called gear shifter mechanism and foot brake mechanism. The operation for both mechanisms will be controlled by microcontroller Arduino Mega and HS-58S relay module.

In gear shifter mechanism, transmission control consist of a permanent magnet DC motor which used to shift a gear lever and a limit switch to detect the position of the gear lever. The permanent mag-net DC motor is mounted at the top of car's automatic transmission or gearbox where the inhibitor switch is located. The inhibitor switch commonly refers as neutral safety switch, which is a safety device that only allows the engine to start when the automatic transmission is in either on Park $(\mathrm{P})$ or Neutral $(\mathrm{N})$ position. The purpose of the neutral safety switch is to prevent the car from starting while in gear, which would cause it to move forward unexpectedly. Unlike the manual transmission system, the gear shifter lever of automatic transmission system is not mounted mechanically to the gearbox but connected electrically through the inhibitor switch. When the gear shifter is moved, the steel cable will drive the inhibitor switch proportional to the gear position.

In this research, the permanent magnet DC motor is used to drive the position of the inhibitor switch automatically. Since the inhibitor switch is connected to the gear shifter lever inside the car, this will result the movement of gear shifter lever proportional to the inhibitor switch position. Hence, the microcontroller Arduino Mega needs to determine the position of the gear shifter lever to ensure that the permanent magnet DC motor is able to shift the gear precisely. To assist the microcontroller in determining the exact position of the gear lever and avoid from over shifted or miss shifted during operation, a limit switch has been used.

Electronic parking brake mechanism consists of a permanent magnet DC motor, wire rope, pulley, and limit switch. It is used to press and release the brake during operation. In electronic parking brake system, the permanent magnet DC motor is mounted under the driver seat while the pulley is mounted near to the brake pedal. One end of a wire rope is attached to the permanent magnet DC motor while the other end is attached to the brake pedal. The permanent magnet DC motor is mounted with rope drum which is used to role the wire rope or release it. The pulley is used to guide a wire rope during the operation. This mechanism allows the system to press and release the brake by controlling the direction of permanent magnet DC motor. However, there is a risk of the wire rope to jump out from the pulley if over rotation occurred when the brake is fully released. Therefore, to keep the wire rope tight, the limit switch is mounted beside the brake pedal with the special bracket designed to cut off the permanent magnet DC motor supply immediately when the brake is completely released to avoid the wire rope jump out from the pulley. Figure 3 shows the whole system for automatic drive vehicle.

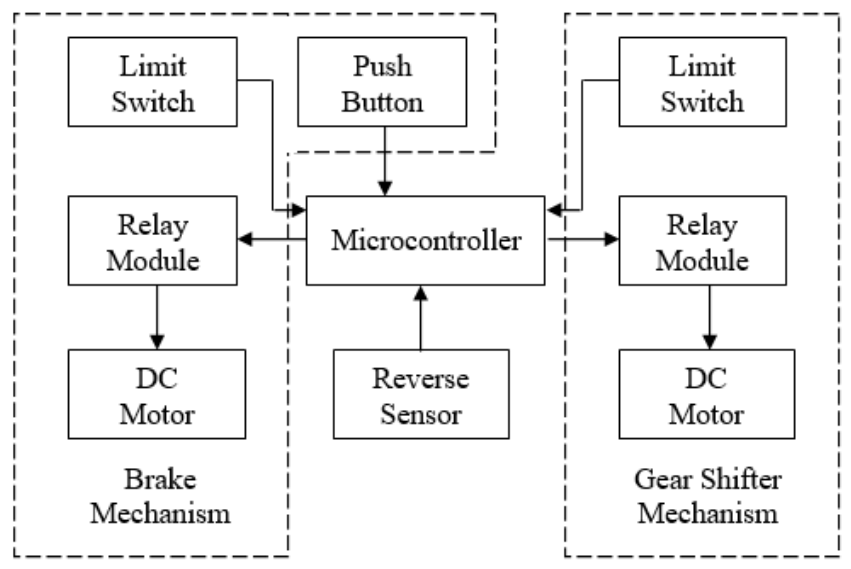

Figure 3: Automatic drive system block diagram 
In automatic drive control, the system has been programmed to provide the coordination and sequence of operation for both mechanisms - brake and gear shifter. After the vehicle successfully start, the microcontroller Arduino Mega will read the initial position of the gear and performed the necessary shifting by rotating the motion of permanent magnet DC motor. This feedback system helps the microcontroller Arduino Mega to drive and stops the permanent magnet DC motor at desired position. After the gear is successful shifted to Reverse (R) gear position, the reverse sensor will start to sense to determine the condition at the back of the vehicle either there is obstacle or not before proceeded to the next process. If there is no obstacle, Arduino Mega will release the brake by controlling another permanent magnet DC motor in brake mechanism for 5 seconds to allow the movement of the vehicle before the brake is pressed again to stop the vehicle. Then, the gear will shifted back from Reverse (R) to Neutral (N) position. Next, the automatic drive system will send a signal to microcontroller to cut off the engine after all the processes are completed. In another situation, when the reverse sensor sense an obstacle behind the car, the Arduino Mega will not release the brake instead of shifted the gear back to Neutral $(\mathrm{N})$ position and send the signal to microcontroller to cut off the engine. The autonomous repositioning system also equipped with a notification system, which is designed base on Global System for Mobile (GSM) communication technology. The system will utilize the Short Message Service (SMS) to send the message to the owner mobile phone every time the repositioning process is completed. The notification system is consists of SIM800L which contains GSM/GPRS module, the GSM antenna, SIM card and it is connected to the microcontroller Arduino Mega. The notification system work is depending on the signal from the automatic drive system. The message will be addressed to the owner mobile phone number which is pre-registered in the system. Two sets of messages are programmed in this system. The first one is to notify the owner that the repositioning process is successful when the process in automatic drive system is completed. The second message is to notify the owner that repositioning process is not successful when the automatic drive system unable to complete the repositioning process due to any obstacle behind the car.

Automatic drive system also programmed to detect real time condition behind the car. This means when the car starts to move the reverse sensor always give the feedback to the microcontroller about the current condition. If there is obstacle appear instantly behind the car, the microcontroller Arduino Mega will received the signal from reverse sensor as interruption and automatically performed the emergency brake by controlling the brake mechanism to stop the car, thus the collision between the car and the obstacle can be avoided. Figure 4 shows the block diagram of the closed loop gear position control.

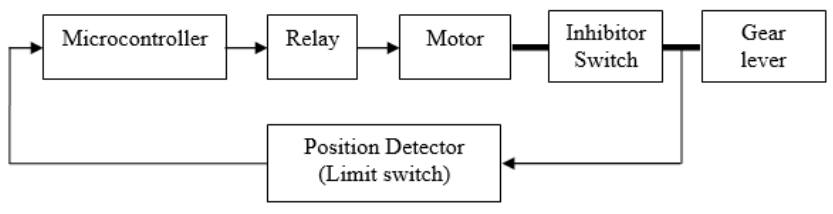

Figure 4: Block diagram of gear position control

\section{RESULTS AND DISCUSSION}

The function of sound recognition system is to start the car's engine by detecting the specific car's horn sound sequence and drive the ignition switch circuit via electromagnetic relay. Initially, the experiment is conducted by using smart phone to provide the sound sources. Then, the sound recognition system will differentiate the horn sounds and evaluate which type of horn could be detect by the system. Each horn sound that are successfully detected by the system will be counted. The system is programmed to allow only 2 seconds delay between each horn to the next horn. If the delay be-tween horns is more than 2 seconds, the counter will automatically reset. After successfully received the horn command, the system executed the next step which is controlling the electromagnetic relay to start the engine. The testing is repeated three times for each horn type to acquire more accurate results. Table 1 shows the experimental result with different type of horn sounds. Five different horns has been used which are Bosch horn, Denso horn, Hella horn, Piaa horn and Nikko horn. Based on the results in Table 1, the sound recognition system successfully detect the sound input from different car horns demonstrated by android application at $87 \%$. It shows that the system can be operated by various type of horn sounds that generated by the android application. Besides, the system is able to analyze either the sound detected is a true command or not.

Table 1: Sound recognition system with different type of horn sounds

\begin{tabular}{|l|c|c|c|c|c|c|}
\hline \multirow{2}{*}{$\begin{array}{c}\text { Horn } \\
\text { Type }\end{array}$} & \multicolumn{2}{|c|}{ Test 1 } & \multicolumn{2}{c|}{ Test 2 } & \multicolumn{2}{c|}{ Test 3 } \\
\cline { 2 - 7 } & $\begin{array}{c}\text { Hound } \\
\text { counted }\end{array}$ & $\begin{array}{c}\text { Engi } \\
\text { ne } \\
\text { start }\end{array}$ & $\begin{array}{c}\text { Horn } \\
\text { sound } \\
\text { counted }\end{array}$ & $\begin{array}{c}\text { Engi } \\
\text { ne } \\
\text { start }\end{array}$ & $\begin{array}{c}\text { Horn } \\
\text { sound } \\
\text { counted }\end{array}$ & $\begin{array}{c}\text { Engi } \\
\text { ne } \\
\text { start }\end{array}$ \\
\hline Bosch & $4 / 4$ & $/$ & $4 / 4$ & $/$ & $4 / 4$ & $/$ \\
\hline Denso & $4 / 4$ & $/$ & $4 / 4$ & $/$ & $4 / 4$ & $/$ \\
\hline Hella & $4 / 4$ & $/$ & $4 / 4$ & $/$ & $3 / 4$ & $\mathrm{x}$ \\
\hline Piaa & $3 / 4$ & $\mathrm{x}$ & $4 / 4$ & $/$ & $4 / 4$ & $/$ \\
\hline Nikko & $4 / 4$ & $/$ & $4 / 4$ & $/$ & $4 / 4$ & $/$ \\
\hline
\end{tabular}

After the test was completed, the system is now ready to be installed on the vehicle. In this experiment, the real car horn is used to give the command for sound recognition system. This experiment is important to ensure that the sound recognition system is able to detect the actual horn command from other vehicle. Then, the system must initiate the repositioning system by turn on the hazard light to give a sign 
for the user and start the tested vehicle engine. During the car movement, the speed does not controlled by any program or mechanism. When the gear shifted to Reverse (R), the car's engine rotates in idle running condition, which is between 600 to $800 \mathrm{rpm}$. During this time, the engine produces a minimum working torque for the car to move. Hence, the speed of movement is depends on the road surface where the car is moving. If the speed is considered as normal on a flat road surface, it will be faster when the car moves towards a declined surface and will be slower or completely stop when it moves toward inclined surface.

The distance of movement is set by programmed the duration of the car to move and the condition of the road either inclined or declined. The maximum speed of movement at flat road surface in idle engine running condition is $5 \mathrm{~km} / \mathrm{h}$. To measure the distance and time relation, the experiment is conducted on a flat road surface. Figure 5 shows the sound recognition system installed on the vehicle and Figure 6 shows a measuring tape is placed on the road to measure the travel distance of the car. The timer is varies from 3 seconds to 7 seconds by programming and the distance is recorded. Usually, the average normal parking space size is around 9 feet or approximate 2.7 meters in width. Therefore, the car must be able to move at least 2.7 meters to provide the space for blocked vehicle to leave the parking space. From the experiment, average travel distance against timer set for the car to move are plotted as shown in Figure 7. By referring to the figure, the suitable time duration for the automated system is chose to be 5 seconds because it allows the average movement distance for 3.45 meters, which is sufficient for the blocked vehicle to leave the parking space.

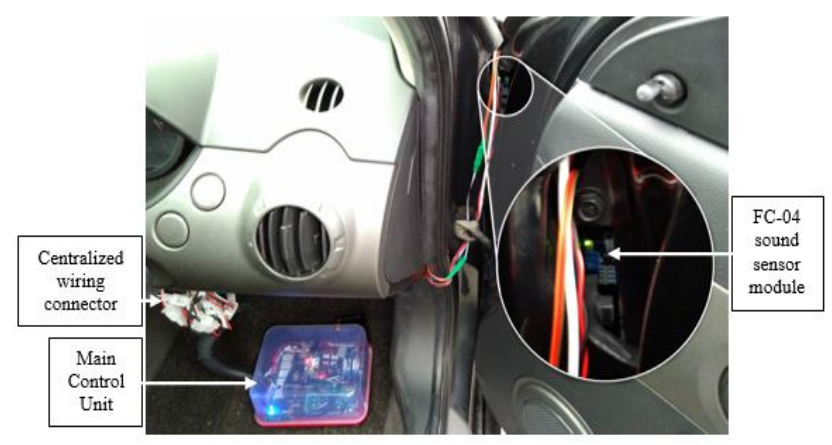

Figure 5: Sound recognition installation

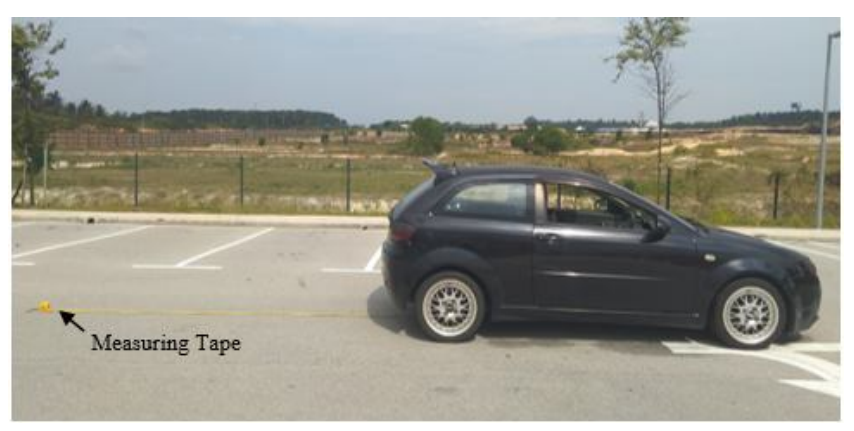

Figure 6: Movement distance measurement

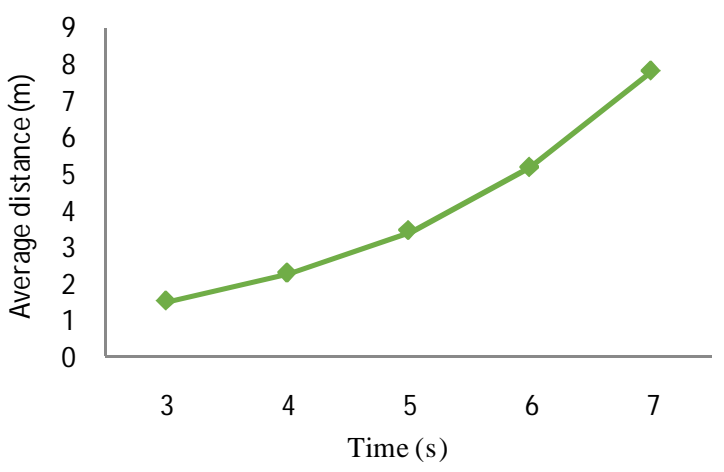

Figure 7: Relationship between distance and time Emergency brake is the safety features in this research to avoid the collision when the repositioning system is running. The emergency brake is programmed to be activated as soon as the reverse sensor detect the obstacle and able to completely stop the car before the collision occurs. The testing for emergency brake has been conducted to evaluate the performance of the autonomous repositioning system. The obstacle used is a set of cardboard boxes with the dimension of $\mathrm{L} 74 \mathrm{~cm} \mathrm{x} \mathrm{W} 28 \mathrm{~cm} \times \mathrm{H} 64 \mathrm{~cm}$ and it is placed behind the car. To have a reliable performance of the emergency brake, the experiment is repeated by varies the initial distance between the vehicle and the obstacle. Then, the final distance after the vehicle completely stop by emergency brake is measured and recorded in Table 2.

Table 2: Emergency brake testing results

\begin{tabular}{|c|c|c|c|c|}
\hline $\begin{array}{c}\text { Initial distance of } \\
\text { obstacle (cm) }\end{array}$ & \multicolumn{3}{|c|}{ Final Distance (m) } & $\begin{array}{c}\text { Average } \\
\text { Distance (m) }\end{array}$ \\
\cline { 2 - 4 } & $\mathbf{1}^{\text {st }}$ & $\mathbf{2}^{\text {nd }}$ & $\mathbf{3}^{\text {rd }}$ & \\
\hline 80 & 80 & 80 & 80 & 80 \\
\hline 100 & 100 & 100 & 100 & 100 \\
\hline 150 & 40 & 45 & 43 & 42.7 \\
\hline 200 & 34 & 36 & 30 & 33.3 \\
\hline 250 & 28 & 25 & 27 & 26.66 \\
\hline 300 & 13 & 10 & 12 & 11.7 \\
\hline
\end{tabular}

From the results shown in Table 2, there is no movement for the obstacle, which is less than $100 \mathrm{~cm}$. The sensor detects the presence of obstacle as soon the automatic drive system initiate. Hence, the brake is not allowed to release by the system. This is because the obstacle is initially located under the sensor operating range. When the obstacle distance is above $100 \mathrm{~cm}$, the brake is released by the system and the car begins to move. Then, the distance between obstacle and the vehicle is decreased as the car moves towards the obstacle until the sensor detect the presence of an obstacle at the distance less than $100 \mathrm{~cm}$. Then, the emergency brake is activated and stop the car to avoid collision.

The significant decrease in final distance can be seen when the initial distance between obstacle and the vehicle is higher because the car is accelerating over time. When reversing, the speed will keep increasing until it reached the equilibrium 
state for engine idle rpm which previously measured at 5 $\mathrm{km} / \mathrm{h}$ at flat road surface. The moment of inertia created by the car make it harder to stop immediately when the brake is pressed. As for the notification system, data is received each time the repositioning system processes completed either the car is successfully repositioned or otherwise. Figure 8 shows the SMS received by the owner in their cell phone either successful or not. With a mobile update, the vehicle owner can keep track of their vehicle movement after leaving it on double-park.

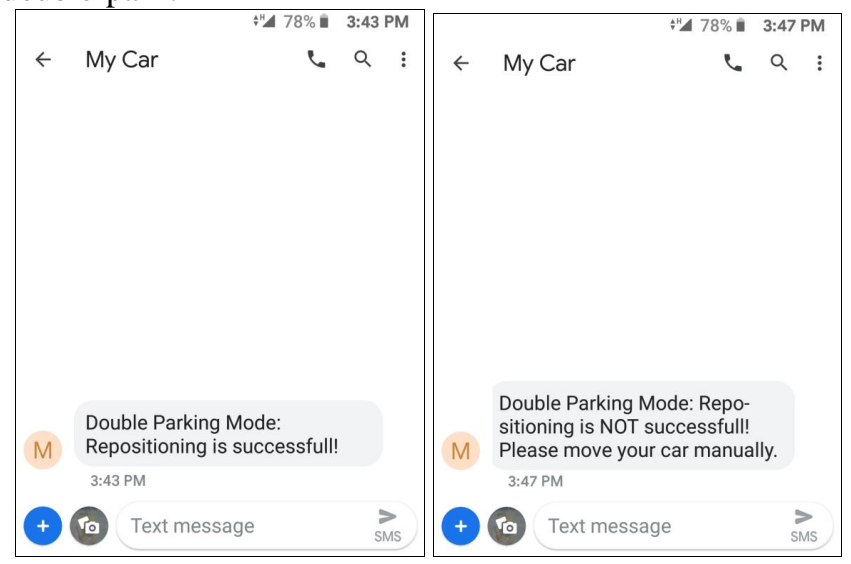

(a)

(b)

Figure 8: (a) SMS received by the owner cell phone successful (b) SMS received by the owner cell phone unsuccessful

After completing several tests and each subsystem shows good results, these subsystems are ready to be combined together to per-form the overall function which is autonomous vehicle repositioning system for double parking condition with notification system. The main control unit will be connected to the centralized wiring connector on the vehicle, including sensors and all designed mechanism as in Figure 9. All external centralized wiring connector are set to male type and the main control unit connector were set to female type so that the connection become easier and safe.

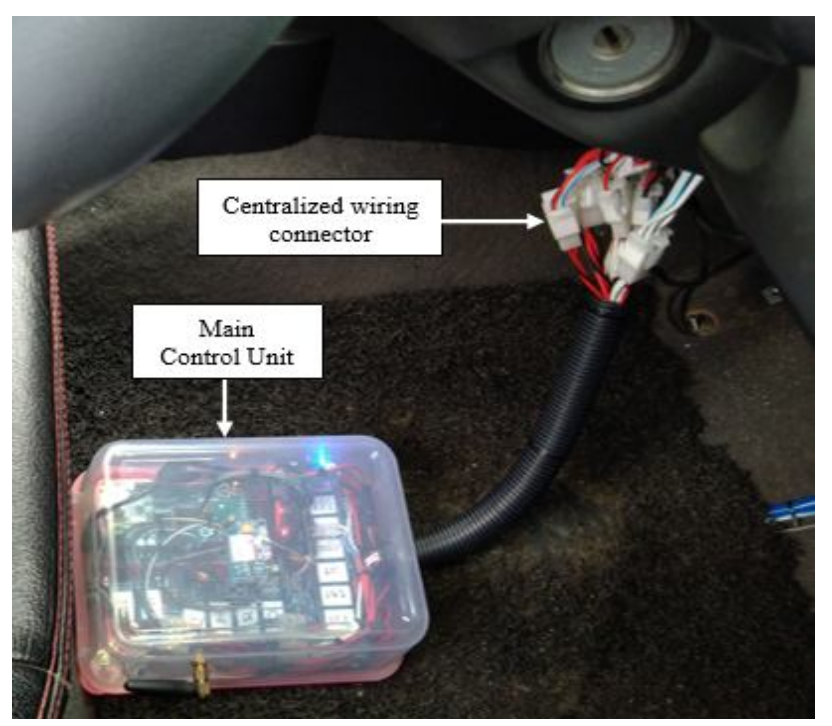

Figure 9: Main control unit connected to external wiring circuit
From the full system testing, it proved that the autonomous repositioning vehicle system able to work with desired functions such as able to start the engine after receiving the horn command from other vehicle, shift the gear from neutral to reverse, control the brake condition to allow the vehicle to move and stop. Then, alter completed, the system will automatically cut off the engine and send SMS notification to the vehicle owner. Figure 10 shows the position of the car before and after repositioning process is completed.

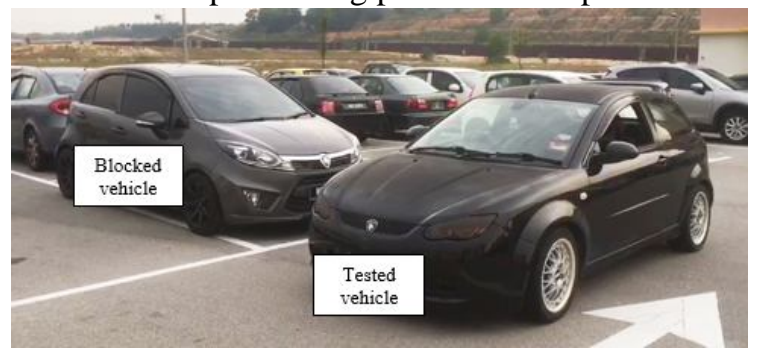

(a)

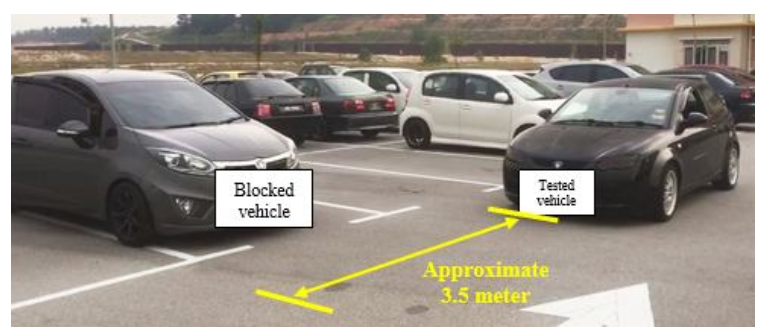

(b)

Figure 10: (a) Vehicle at double parking condition in initial position (b) Vehicle at double parking condition already moved in final position

\section{CONCLUSION}

Based on the results presented, an autonomous vehicle repositioning system for double parking condition has been successfully developed and function as desired. The sound recognition system is able to detect the horn command from blocked vehicle and then automatically start the engine. Next, the automatic drive system is able to perform gear shifter and control the vehicle foot brake to allow the vehicle to move and stop in linear direction. Furthermore, it shows the ability to detect the real time obstacle during repositioning process and perform emergency brake when necessary. Hence, collision between vehicle and any obstacles along its travel path can be avoided. The notification system can provide the status of the vehicle to the owner by sending the SMS after the repositioning process is done or undone due to any obstacles. The owner will get immediate response from the system and take the alternative to move their vehicle manually if the repositioning is not successful.

In short, this research can provide solution for automobile user to leave the parking area faster when they stuck on double parking condition. The victim of double parking will 
not have to push the double-parked vehicle to move it manually or contact the owner and wait for the vehicle to be moved. It can be done by pushing their vehicle's horn to command the double-parked vehicle to move. This research also provides the automobile user an alternative to double park their vehicle when desperate to find a free parking lot without causing a big problem to other parking user. This method seems practical to solve the double-parking problem especially in residential apartment parking area which has low traffic flow.

\section{ACKNOWLEDGEMENT}

The authors would like to give special thanks to Universiti Tun Hussein Onn Malaysia (UTHM) under UTHM-Tier 1 Grant No. H136 and Ministry of Education (MOE) Malaysia for their help and support.

\section{REFERENCES}

1. A. Klappenecker, H. Lee, and J. L. Welch. Finding available parking spaces made easy, Ad Hoc Networks, vol. 12, pp.243-249, 2014.

2. S. Yang, W. Ma, X. Pi, and S. Qian. A deep learning approach to real-time parking occupancy prediction in transportation networks incorporating multiple spatio-temporal data sources, Transportation Research Part C: Emerging Technologies, vol. 107, pp. 248-265, 2019.

3. A. Tsakalidis and P. Tsoleridis. The impacts of illegal parking on the urban areas' traffic and environmental conditions: the case of the city of Thessaloniki, Spatium, pp.41-46, 2015.

4. S. K. Gehrig and F. J. Stein. Dead reckoning and cartography using stereo vision for an autonomous car, in Proceedings 1999 IEEE/RSJ International Conference on Intelligent Robots and Systems, vol. 3, pp. 1507-1512, 1999.

5. T. Rajabioun, B. Foster, and P. Ioannou. Intelligent parking assist, in IEEE 21 st Mediterranean Conference on Control and Automation, pp. 1156-1161, 2013.

6. R. Estepa, A. Estepa, J. Wideberg, M. Jonasson, and A. Stensson-Trigell. More effective use of urban space by autonomous double parking, Journal of Advanced Transportation, vol. 2017, pp. 1-10, 2017. https://doi.org/10.1155/2017/8426946

7. US Software System Safety Working Group. Adaptive Cruise Control System Overview, in 5th Meeting of the US Software System Safety Working Group, pp. 1-7, 2005.

8. A. Abosekeen, T. B. Karamat, A. Noureldin, and M. J. Korenberg. Adaptive cruise control radar-based positioning in GNSS challenging environment, IET Radar, Sonar \& Navigation, vol. 13, no. 10, pp. 1666-1677, 2019.
9. S. Geronimi, V. Abadie, and N. Becker. Methodology to assess and to validate the dependability of an advanced driver assistance system (ADAS) such as automatic emergency braking system (AEBS), in Energy Consumption and Autonomous Driving, Springer, Cham, pp. 125-131, 2016.

10. O. Garcia-Bedoya, S. Hirota, and J. V. Ferreira. Control system design for an Automatic Emergency Braking system in a sedan vehicle, in 2nd Latin American Conference on Intelligent Transportation Systems, pp. $1-6,2019$.

11. A. Ghasempour, Z. M. Hanapi, M. Salehi, and Z. Vahdati. Using traffic control scheme in Intelligent Transportation System, International Journal of Advanced Trends in Computer Science and Engineering, vol. 8, no. 1.4, pp. 165-172, 2019. https://doi.org/10.30534/ijatcse/2019/2581.42019

12. S. R. Khan, A. Al Mansur, A. Kabir, S. Jaman, and N. Chowdhury. Design and Implementation of Low Cost Home Security System using GSM Network, in International Journal of Scientific \& Engineering Research, vol. 3, no. 3, pp. 1-6, 2012.

13. A. D. M. Africa, R. S. A. Charmaine, M. E. O. Lagula, A. A. Latina, Jr., and D. T. Charmaine. Mobile Phone Graphical User Interface (GUI) for Appliance Remote Control: An SMS-based Electronic Appliance Monitoring and Control System, International Journal of Advanced Trends in Computer Science and Engineering, vol. 8, no. 3, pp. 487-494, 2019.

https://doi.org/10.30534/ijatcse/2019/23832019

14. E. B. Panganiban. Automated Hazardous Gas Detecting Robot using Wireless Sensor Networks with GSM-SMS Alert and Fire Control System for Households, International Journal of Advanced Trends in Computer Science and Engineering, vol. 8, no. 3, pp. 804-809, 2019. https://doi.org/10.30534/ijatcse/2019/72832019 